\title{
EFFECT OF FLY ASH ADDITION ON THE FRACTURE TOUGHNESS OF PLAIN CONCRETE AT THIRD MODEL OF FRACTURE
}

\author{
Grzegorz Ludwik GOLEWSKI \\ Department of Structural Engineering, Faculty of Civil Engineering and Architecture, \\ Lublin University of Technology, Nadbystrzycka 40 str., 20-618 Lublin, Poland
}

Received 19 Apr 2016; accepted 21 Jun 2016

\begin{abstract}
A new testing method and estimation of the fracture toughness in Mode III (antiplane shear) of concretes containing: 0, 20 and 30\% volume content of the class F fly ash (FA) was proposed. Fracture toughness tests were performed on axial torsional machine MTS 809 Axial/Torsional Test System using special device. The Device for the fracture toughness test at the Mode III fracture consisted of the cylindrical specimen with the formed initial crack, steel plates, and screws with washers securing the specimen in the press holders. The specimens applied for experiments were cylinders with dimensions of $150 / 300 \mathrm{~mm}$, having an initial circumferential notch made in the half-height of cylinders. The specimens were subjected to pure torsion. The studies examined effect of FA additive on the parameter $K_{\text {IIIc }} .20 \%$ FA additive causes a small increase of the $K_{I I I c}$ in comparison to the concrete without the FA, while $30 \%$ FA additive causes a significant decrease in fracture toughness. The fracture surfaces of the specimens analysed macroscopically were planar. Scanning microscopic observations (SEM) indicate that in the fracture surfaces multilevel cracks occur in the shape of semicircles.
\end{abstract}

Keywords: concrete, fly ash, third model of fracture, torsional loading, fracture toughness, fracture surface.

\section{Introduction and literature review}

Acquisition of natural raw materials and fuels for the economy in Poland and in the world is becoming an increasing problem. The branches of economics that consume a lot of energy and raw materials include the construction materials industry, especially the cement and concrete industry. Therefore, a very important issue is to find cheap and fully useful materials of mineral origin that will be able to replace the most expensive component in the composition of cement, which is the Portland cement clinker. Principles of sustained development and ecology are an important issue in design of concrete compositions (Konkol, Prokopski 2014). Moreover, reduced use of primary construction materials and a greater share of recycled materials should be regarded as priorities of the industry (Grinys et al. 2015).

Nowadays, different types of waste are used as additives to concrete in order to improve its durability, strength and fracture toughness (Meyer 2009; JóźwiakNiedźwiedzka et al. 2012; Stehlík 2013; Konkol, Prokopski 2014; Grinys et al. 2013, 2015). One of these materials is siliceous fly ash (FA) which is a by-product obtained in the process of hard coal combustion performed in electric power stations and in thermal-electric power stations (Ahmaruzzaman 2010). Since thermal and electrical energy in Poland in more than $90 \%$ is produced in coal combustion processes, approximately 20 million tons of siliceous FA is produced each year (Kurdowski 2014). Such large quantities of waste in the absence of its management require the construction, maintenance and protection of facilities responsible for those wastes, which is a major environmental and social problem. In order to reduce large quantities of FA, the by-products of coal combustion in $20^{\text {th }}$ century began to be used as a nutritious additive for cement and concrete. Currently, the cement industry is one of the major areas of the economy, which on a large scale is able to utilize emerging, in the hard coal combustion processes, combustion by-products which are FA. Treatments of this type are beneficial for ecological reasons due to reducing the deposit areas of troublesome industrial wastes as well as the economic reasons because of the possibility to replace part of the cement binder in the concrete with FA treated as pozzolanically active microfillers. Additionally, concrete with fly ash is characterised by advantageous applicable qualities (Kosior-Kazberuk, Lelusz 2007) and has important effect in strength of concrete (Liu, Wang 2011). Data of investigations on hardened concrete showed that fly ash increases compressive strength, plastic deformations and modulus of elasticity, decreases shrinkage strains and modifies other concrete properties (Rudžionis, Ivanaus-

Corresponding author: Grzegorz Ludwik Golewski

E-mail: g.golewski@pollub.pl 
kas 2004). For these reasons, a good quality siliceous FA is used for production of Portland-composite cement and plain concretes as well as concretes with higher strengths - inc. high performance concretes (Poon et al. 2000) and ultra-high performance concretes (Yu et al. 2015). Siliceous FA are also used to produce other types of concrete composites, e.g. self-compacting concretes (Holschemacher 2004) and composites with hybrid binders (Lam et al. 1998; Snelson et al. 2011; Rathish Kumar et al. 2014). An interesting and important use of the FA in the composite materials industry is application of these wastes in the synthesis of carbon nanomaterials such as: nanotubes, nanofibers or graphene (Nasibulin et al. 2013). These waste materials are also particularly useful in environment protection, e.g.: as the adsorbents of harmful compounds, or as components of cement binders used for the immobilization of heavy metals (Giergiczny, Król 2008).

\section{Research significance}

Failure of concretes is a multi-stage process that is conditioned by level and type of applied external loads as well as by internal structure of composite (Xia et al. 2012; Gorzelańczyk, Hoła 2015). The reduction of strength of concrete results from initial structural defects existing inside material (Sadowski, Golewski 2008). According to Jacobsen et al. (2013), an important issue in the modeling of the fracture processes in concrete is a description of the topography of the crack surface. On the other hand a description of the processes of crack initiation and propagation in a material requires the knowledge of all fracture mechanics parameters, i.e. $K_{I c}, K_{I I c}$ and $K_{I I I c}$ (Sadowski, Golewski 2008). This is due to the fact that the cracks in structural elements usually start to initiate in the mixed mode loading (Song et al. 2004).

Up till now the effect of FA influence on the fracture toughness of the concrete composites was not investigated systematically and rather. Fracture toughness under Mode I for plain and high performance concretes containing siliceous FA studied by Lam et al. (1998), Bharatkumar et al. (2005), Vejmelkova et al. (2009), Zhang and Li (2013). Golewski and Sadowski (2014), presents the values of the fracture toughness for the Mode II $\left(K_{I I c}\right)$ for plain concretes and modified concretes with the $10 \%$, $20 \%$ and $30 \%$ class F FA additives. The tests done with Compact Shear Specimens showed that the $10 \%$ and $20 \%$ FA additive cause the increase of the $K_{I I c}$ by $1.9 \%$ and $3.5 \%$. The replacement of portion of cement with the $30 \%$ FA additive reduces the $K_{\text {IIc }}$ by $13.9 \%$. The results obtained in experimental studies were also confirmed numerically by analysis of the 3D fracture processes, using $\mathrm{X}$-FEM method and ABAQUS program. Clear convergence of experimental results with numerical calculations have been observed both in the young concrete (Golewski, Sadowski 2012) and mature concrete (Golewski et al. 2012).
Investigations of the Mode III fracture toughness at for different types of materials have been carried out since the 80 's of the last century for: ceramic materials, steel alloys, wooden materials and piezoelectric materials. The first and probably only available in the literature results of fracture toughness tests of concretes at the Mode III fracture were presented by Bazant and Prat (1988) and Bazant et al. (1990). According to the author knowledge there are no studies on Mode III fracture toughness for the concretes with the FA additives.

Therefore this paper provides a new test method and new experimental results concerning $K_{I I I c}$ in the investigated concretes. The importance of the fracture toughness in the antiplane shear (Bazant et al. 1990) is particularly visible in the analysis of structures subjected to torsion such as: slab, beams bent in the plan, end-beams in ceilings, balcony slab ring beams, girders of spatial frames, spiral stars, crane beams, T-beams and other. Selected examples of reinforced and prestressed concrete elements loaded in torsion were shown by Kamiński and Pawlak (2011) and Bernardo et al. (2013). An analysis of reinforced concrete elements subjected to torsion is important especially in the state II of construction, i.e. cracked phase. In this case torsional loads lead to a larger loss of stiffness in state II, due to the strong cracking, than the loss of flexural stiffness (Lopes et al. 2014). In particular, the paper contains the comparative analysis of the fracture toughness $K_{\text {IIIC }}$ of the plain concretes and ones modified by the siliceous FA additive. The experiments were done with the same concretes composition tested earlier in the Mode II fracture (Golewski, Sadowski 2012, 2014; Golewski et al. 2012). It was found, that $10 \%$ siliceous FA additive slightly affects the value of the parameter $K_{I I c}$ causing its increase by only $1 \%$, whereas $20 \%$ and $30 \%$ FA additives significantly change the fracture toughness of concrete. $20 \%$ siliceous FA additive affects the increase of fracture toughness of concrete by a few percent, while replacement of the cement in the concrete mix with larger quantity of the FA decreases the $K_{I I c}$ more than $10 \%$ (Golewski, Sadowski 2014). In this paper the $K_{\text {IIIc }}$ fracture toughness tests and the $f_{\mathrm{cm}}$ compressive strength tests were conducted on three types of concretes of different amount of the siliceous FA additive:

- without the FA additive: FA-00;

- with 20\% FA additive: FA-20;

- with 30\% FA additive: FA-30.

\section{Experimental investigation}

\subsection{Materials}

Tests were carried out for concretes contained commercial Ordinary Portland Cement (OPC) CEM I 32.5 R, with the Blaine fineness $3300 \mathrm{~cm}^{2} / \mathrm{g}$ and compressive strength equal to $50 \mathrm{MPa}$ after 28 days of curing. The mineralogical composition of clinkers in cement used is presented in Table 1. The fine aggregate used was pit sand with a maximum diameter of $2 \mathrm{~mm}$, the coarse 
Table 1. Chemical composition of the OPC and the FA [mass \%]

\begin{tabular}{cccccccccccc}
\hline Component & $\mathrm{SiO}_{2}$ & $\mathrm{Al}_{2} \mathrm{O}_{3}$ & $\mathrm{CaO}$ & $\mathrm{MgO}$ & $\mathrm{SO}_{3}$ & $\mathrm{Fe}_{2} \mathrm{O}_{3}$ & $\mathrm{LOI}$ & $\mathrm{C}_{3} \mathrm{~S}$ & $\mathrm{C}_{2} \mathrm{~S}$ & $\mathrm{C}_{3} \mathrm{~A}$ & $\mathrm{C}_{4} \mathrm{AF}$ \\
\hline OPC & 21.37 & 5.02 & 63.95 & 2.47 & 3.0 & 2.4 & 1.24 & 60.69 & 15.82 & 9.24 & 7.28 \\
$\mathrm{FA}$ & 50.96 & 25.88 & 2.15 & 2.6 & 0.65 & 8.25 & 3.2 & - & - & - & - \\
\hline
\end{tabular}

aggregate - natural gravel aggregate with a maximum diameter of $8 \mathrm{~mm}$.

Siliceous FA from local power plant was used. It was obtained in high temperature process. The chemical constituents of the FA are shown in Table 1. The FA is a class $\mathrm{F}$ with $85.09 \%$ of $\mathrm{SiO}_{2}+\mathrm{Al}_{2} \mathrm{O}_{3}+\mathrm{Fe}_{2} \mathrm{O}_{3}, 0.65 \%$ of $\mathrm{SO}_{3}$ and $3.2 \%$ of Loss of Ignition (LOI) meeting the requirement of ASTM C618. The crystalline phases of the FA were identified by XRD patterns. The X-ray diffractogram of the FA (Fig. 1) shows that there are, beside glass, four major crystalline components in the phase composition of the FA: quartz $\left(\mathrm{SiO}_{2}\right)$, mullite $\left(\mathrm{Al}_{6} \mathrm{Si}_{2} \mathrm{O}_{13}\right)$, magnetite $\left(\mathrm{Fe}_{3} \mathrm{O}_{4}\right)$ and hematite $\left(\mathrm{Fe}_{2} \mathrm{O}_{3}\right)$. A glass phases content and crystalline phases content in siliceous FA was investigated by the Rietvield quantitative analysis. The glass content in FA was $71.5 \%$. The contents of the remaining phases determined by Rietveld analysis were: quartz $-19.7 \%$ and mullite $-8.8 \%$. The Blaine fineness of the FA is $3600 \mathrm{~cm}^{2} / \mathrm{g}$, whereas the specific gravity is 2.14. Pozzolanic activity of the FA was evaluated according to standard EN 450-1. Strength activity index tests of the FA indicated that this activity was: after 28 days $-92 \%$, while after 90 days $-111 \%$. Microstructure of the FA used in tests was presented by Golewski (2015). These studies showed very small finess of the FA (a few to $50 \mu \mathrm{m}$ ) and characteristic cenospheres. Small particle size of the FA has a beneficial effect on compressive strength, durability and permeability of concretes with these additives and is helpful in improving the transition zone characteristics through processes of pore refinement and grain refinement (Mehta, Monteiro 1987).

\subsection{Mix proportions and specimen preparations}

The methodology used for determining the composition of the mixtures consisted in replacing a suitable amount of cement volume (weight volume content) in the mixture

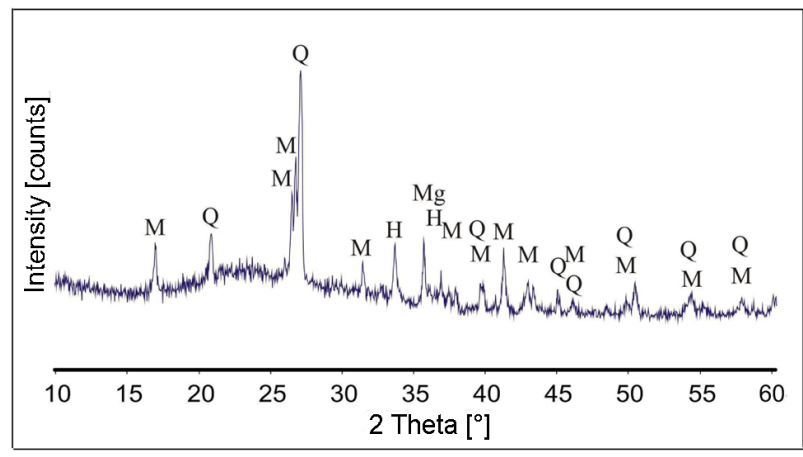

Fig. 1. XRD pattern of FA used ( $\mathrm{Q}$ - quartz, $\mathrm{M}-$ mullite, $\mathrm{Mg}$ - magnetite, $\mathrm{H}$ - hematite) with a corresponding amount of the FA to ensure that the total amount of binding material is always constant (Kosior-Kazberuk, Lelusz 2007). Tests were carried out on concrete specimens prepared of mixtures with 2 different values of FA content related to cement mass, as well as on unmodified control specimens (see chapter 1). The cement content in control concrete, i.e. FA-00 was $352 \mathrm{~kg} / \mathrm{m}^{3}$. A water to binder ratio in the tested concretes was constant $(w / b=0.40)$.

The cast specimens were covered with polyurethane sheet and damped cloth and placed in $20 \pm 2{ }^{\circ} \mathrm{C}$ chamber. All specimens were demoulded at the age of 2 days. Then they were kept for 14 days in a chamber with a moisture-saturated atmosphere and for another 14 days under laboratory conditions $\left(20 \pm 2{ }^{\circ} \mathrm{C}\right)$. After 28 days of curing the compressive strength tests and other basic tests were carried out. In order to decrease the dispersion of the test data, 6 specimens were prepared for each mixture (both in the test of the compressive strength and fracture toughness).

\subsection{Compressive strength analysis}

The uniaxial compression strengths were tested using a compression machine (Walter + Bai ag) with a maximum load of $3000 \mathrm{kN}$. The compressive strengths $\left(f_{c m}\right)$ were tested with application of cubic specimens $(150 \mathrm{~mm}) \mathrm{ac}-$ cording to the standards of series EN 12390. The loading rate of compressive strength test was controlled between $0.5 \mathrm{MPa} / \mathrm{s}$ and $0.8 \mathrm{MPa} / \mathrm{s}$.

\subsection{Fracture toughness tests during Mode III loading}

In order to determine the fracture toughness $K_{I I I c}$, cylindrical specimens with a diameter of $150 \mathrm{~mm}$ and a height of $300 \mathrm{~mm}$ having an initial circumferential notch of $2 \mathrm{~mm}$ thickness were tested (Bazant, Prat 1988; Bazant et al. 1990) (Fig. 2). Initial notch depth was equal to $1 / 4$ of the diameter of the cylinders. Initial notches in the specimens were created during their formation by application of 2 semi-circular steel inserts placed in the half-height of specially prepared cylindrical forms.

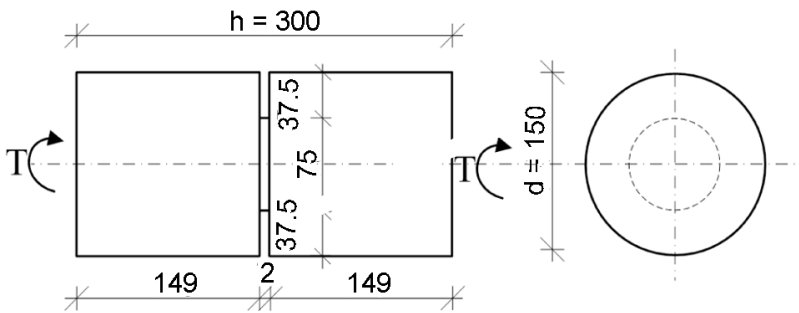

Fig. 2. Geometrical configuration of tested specimen (dimensions in $\mathrm{mm}, T$ - torque) 


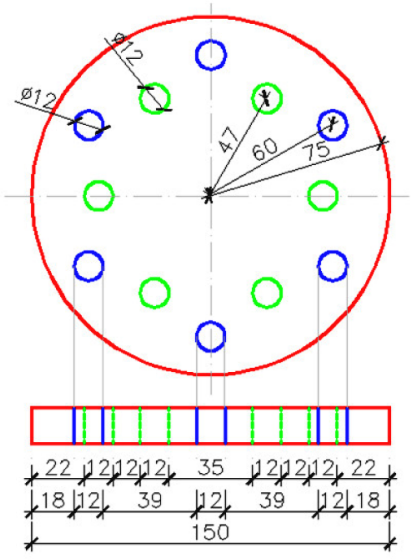

a)

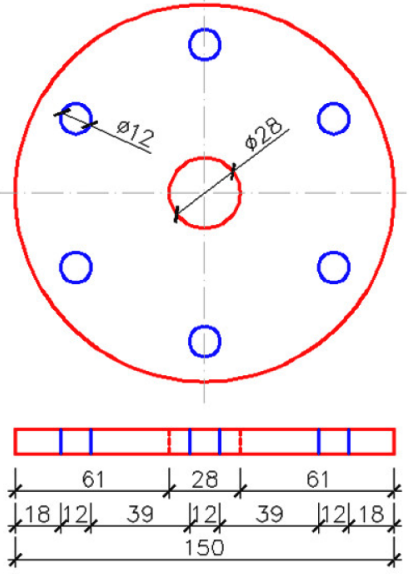

b)

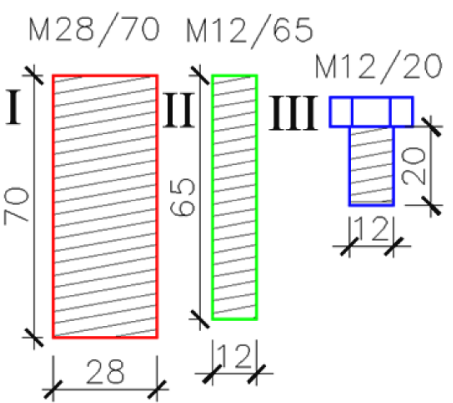

c)

Fig. 3. Steel plates and bolts used for fixing the specimens in the torsion testing machine: a) bottom plate, b) top plate, c) bolts (dimensions in $\mathrm{mm}$ )

In order to carry out basic research a special device was manufactured. The Device for the Mode III fracture toughness tests consists the cylindrical specimen with the initial notch (Fig. 2), steel plates, and screws with washers securing the specimen in the press holders. To mount the specimens in the grips of the torsional testing machine, 2 types of circular steel plates with drilled holes were designed and manufactured (Fig. 3). During forming, the bottom plates of $15 \mathrm{~mm}$ thickness (Fig. 3a) were anchored in the specimens on their top and bottom through 6 bolts M12/65 (Fig. 3c-II). Then, top plates of $10 \mathrm{~mm}$ thickness (Fig. 3b) were bolted to these plates through 6 bolts M12/20 (Fig. 3c-III). Top plates hold the specimen directly in the grips of the torsional testing machine from the top and bottom through M28/70 bolts (Fig. 3c-I). The full device for testing the $K_{I I I c}$ is shown in Figure 4.

The specimens were tested on the axial torsional testing machine MTS 809 Axial/Torsional Test System in accordance with the load diagram shown in Figure 4.

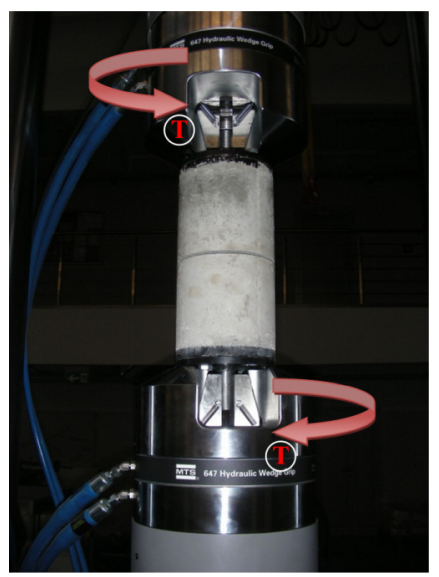

Fig. 4. The experimental stand with the fixed device subjected to torsion $(T-$ torque $)$
In a similar manner, the fracture toughness test $K_{I C}$ on cylindrical specimens with an initial spiral notch was carried out by Wang et al. (2010). During experiments, the angle of rotation $(\theta)$ was steered at the zero axial force. A small increase in $\theta$ at $0.5^{\circ} / \mathrm{min}$ was assumed, so that a critical torque $\left(T_{Q}\right)$ is reached after a few minutes after the start of testing. Values $T_{Q}$ and $\theta$, at which the failure of the specimens occurred, were recorded in the tests.

On the basis of the experimental results, fracture toughness $K_{\text {IIIC }}$ can be concluded, which was determined according to the Eqn (1) (Miannay 1998):

$$
K_{\text {IIIIC }}=\frac{\tau_{\max } \cdot \sqrt{2 \pi r}}{\cos \left(\frac{\theta}{2}\right)},
$$

where: $\tau_{\max }$ - maximum stress [MPa]; $r$ - radius of twisted surface $[\mathrm{m}] ; \theta$ - angle at which the specimen failed [deg].

\section{Results and discussion}

\subsection{Analysis of compressive strength test results}

Table 2 shows the average results of the compressive strength of concretes containing the FA with statistic parameters (standard deviation $-s$ and coefficient of variation $-v$ ). Based on the obtained results, it can be concluded that the $20 \%$ additive causes an increase $f_{c m}$ after 28 days of curing by 3.1 percent, while the $30 \%$ FA additive causes a drop of this parameter by 5.1 percent.

\subsection{Analysis of fracture taughness $K_{\text {IIIc }}$ test results}

Based on the data recorded during the tests, graphs of: angle of rotation $(\theta)$ vs time $(t)$, torque ( $T$ ) vs $t$ and $T$ vs $\theta$ were plotted and values of fracture toughness were calculated. The average values of the fracture toughness after 28 days of curing with statistic parameters $s$ and $v$ 
Table 2. Compressive strength of concretes

\begin{tabular}{llcc}
\hline Concrete & \multicolumn{1}{c}{ Compressive strength [MPa] } & $s[\mathrm{MPa}]$ & $v[\%]$ \\
\hline FA-00 & $47.51-(100 \%-$ comparative concrete $)$ & 2.55 & 4.58 \\
FA-20 & $48.96-(103.1 \%$ in relation to FA-00 $)$ & 3.02 & 7.53 \\
FA-30 & $45.10-(94.9 \%$ in relation to FA-00 $)$ & 3.25 & 7.87 \\
\hline
\end{tabular}

Table 3. Fracture toughness $K_{\text {IIIC }}$ of concretes

\begin{tabular}{clcc}
\hline Concrete & \multicolumn{1}{c}{ Fracture toughness $K_{\text {IIIc }}\left[\mathrm{MN} / \mathrm{m}^{3 / 2}\right]$} & $s\left[\mathrm{MN} / \mathrm{m}^{3 / 2}\right]$ & $v[\%]$ \\
\hline FA-00 & $2.49-(100 \%$ - comparative concrete $)$ & 0.20 & 8.03 \\
FA-20 & $2.60-(104.4 \%$ in relation to FA-00 $)$ & 0.24 & 9.23 \\
FA-30 & $2.14-(85.9 \%$ in relation to FA-00 $)$ & 0.21 & 9.81 \\
\hline
\end{tabular}

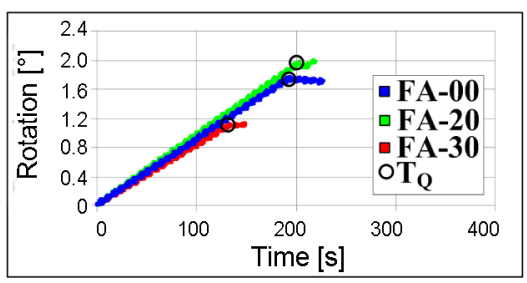

a)

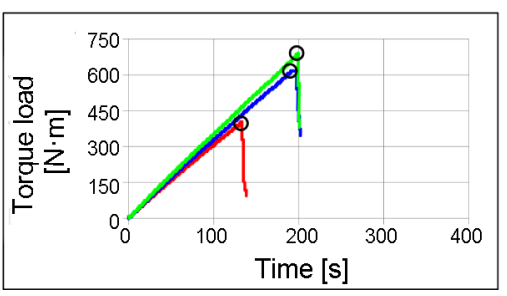

b)

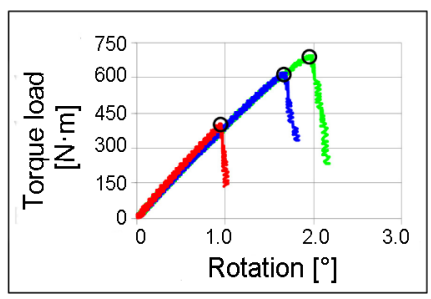

c)

Fig. 5. Examples of graphs obtained from the testing: a) $\theta$ vs $t$; b) $T$ vs $t$; c) $T$ vs $\theta$

are gathered in Table 3, whereas examples of graphs of the analysed relationships for one of the specimens (for all series of concrete) are shown in Figure 5.

The failure, i.e. the moment when the specimen no longer carry the torque, is usually characterized by:

- a sudden collapse on the graph $T-\theta$ (Fig. 5c);

- a constant value $\theta$ maintained for at least several seconds (Fig. 5a).

All specimens during testing underwent planar failures at the point where initial cracks were filled within a few minutes after the application of the load. Figure 6 shows a view of tested specimen with marked in green connection points of concreted inserts that are forming

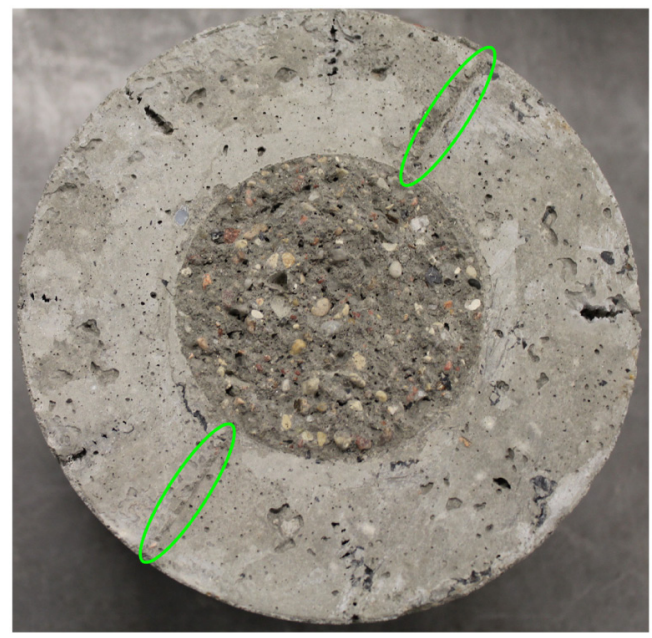

Fig. 6. A view of fractured specimen after the fracture toughness test, showing the failure surface the initial cracks. It shows a characteristic planar fracture surface. The same type of fracture is also presented by Bazant et al. (1990).

In order to precise evaluation of fracture surface, a microscopic observation was carried out. The microstructural analysis was done by application of the Scanning Electron Microscope (SEM) to assess the morphology of the fractured concrete surfaces. The microstructural testing was carried out using a QUANTA FEG 250. Figure 7 shows the characteristic image of the concrete microstructure obtained from the SEM observations. In general, multilevel cracks in the shape of half-circles and in accordance with the direction of the torque could be observed (Fig. 7).

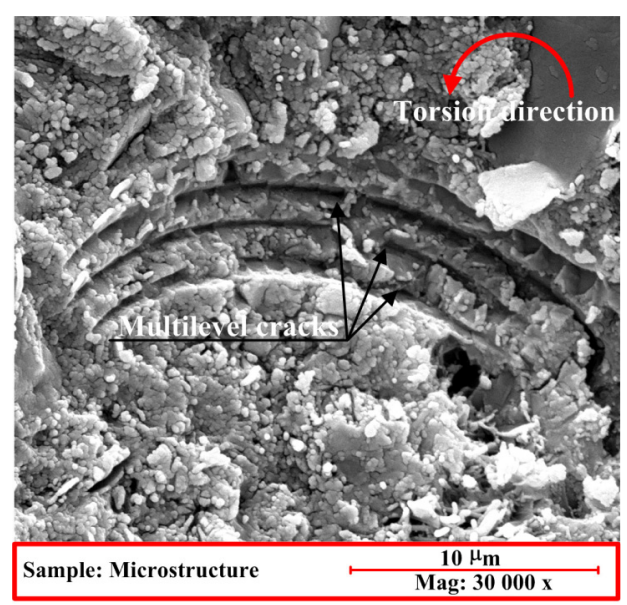

Fig. 7. Microstructure of the fractured concrete surface 
The obtained results lead to conclusion that the $20 \%$ FA addition caused increase of $K_{I I I c}$ by $4.4 \%$, while the replacement of a part of cement with a $30 \%$ additive of the FA brings about $14.1 \%$ reduction of the fracture toughness in comparison to the concrete without the FA. The above results are partially convergent with the results of the compression strength tests (Table 2). The increase of $f_{c m}$ in case of composite FA-20 and the decrease of this parameter in case of the composite with a $30 \%$ addition of this filling material were observed. Similar trends in obtained results were observed when testing the same composites at the Mode I fracture and Mode II fracture (Golewski et al. 2012; Golewski, Sadowski 2014). The average values of the fracture toughness $K_{I c}$ and $K_{I I c}$ with statistic parameters $s$ and $v$ are gathered in Table 4 and Table 5. One can observe also greater dispersions of the obtained results (increased values of the coefficient of variation) in the case of modified concretes, e.g. almost $10 \%$ in case of the $K_{I I I c}$ and more than $10 \%$ in case of the $K_{I c}$ and $K_{I I c}$. This phenomenon is associated with the presence (after 28 days of curing) unhydrated FA particles (mainly in the case of concrete containing 30\% FA additive). These specific areas could contain local zones of increased heterogeneity of the material. It was confirmed in the microstructural studies (e.g. Mehta, Monteiro 1987; Zhang 1995; Golewski, Sadowski 2014). Furthermore, large addition of FA for concrete significantly changes: the microstructure, mechanical properties and direction of crack propagation (Zhang 1995). For these reasons in the concrete containing fly ash can be observed a greater dispersion of test results (Tables 2-5).

Based on a comparison of the values of the fracture toughness for all three modes of cracking, it was found that the ratio $K_{I I I} / K_{I C}$ amounted to 2.35, 2.30 and 2.39 for concrete FA-00, FA-20 and FA-30, respectively; whereas the value $K_{I I I c} / K_{I I c}$ for all series of concrete was equal to 0.59 . High similarity in the obtained results, particularly in comparison to the fracture toughness $K_{I I I c}$ to $K_{I I c}$, can indicate a very accurate and precise testing for all analysed modes of cracking. Moreover, when comparing the results from the testing for Mode I, II and III fracture, a greater accuracy (smaller coefficients of variation) of results $K_{\text {IIIc }}$ in comparison to $K_{I c}$ and $K_{I I c}$ was observed. This might have been due to: precise preparation of specimen by preparing the special device for fracture toughness and the use of very precise axial torsion machine MTS 809 with recording the results on a computer (Fig. 4).

Modification of the concrete structure with active mineral additives, such as the FA, is justified by ecological as well as economic reasons. The tests showed that this active filing material has beneficial influence on delaying the destructive processes in the material and on the increase of the material's fracture toughness. The replacement of $20 \%$ of cement with the additive of active pozzolana class F FA caused the increase of the $K_{\text {IIIc }}$ (Table 3) parameter of the concrete after 28 days of curing. Moreover, it was observed that the concrete from the batch FA-20 had higher compression strength than the concrete without additives (Table 2). Similar positive results of compressive strength of composites with 20\% FA additive observed by Chindaprasirt and Rukzon (2008) - during testing of mortar and Ratish Kumar et al. (2014) - during testing of concrete.

The beneficial effect of $20 \%$ siliceous FA addition on the parameters of different composites was also observed in the studies (Sekulic et al. 1999; Jing et al. 2008; $\mathrm{Xu}$ et al. 2012; Lee et al. 2012; Sabet et al. 2013; Nadeem et al. 2014). Based on these tests, it was found that the additive of siliceous FA in the amount of $20 \%$ is beneficial for:

- increase in the specific surface area of mechanically activated FA (Sekulic et al. 1999);

- increase in the tobermorite phase (Jing et al. 2008);

- reduction in thickness of the corrosion layer in the reinforcement bars in the contact layer with concrete (Xu et al. 2012);

- increase of the C-S-H phase after: 28, 56 and 91 days of curing (Lee et al. 2012);

- significant increase in electrical sensivity of SCHP concrete (Sabet et al. 2013);

- better performance of concrete at temperatures oft $400{ }^{\circ} \mathrm{C}$ and above (Nadeem et al. 2014).

After 28 days of curing, the composites containing $30 \%$ addition of FA were characterized by lower strength

Table 4. Fracture toughness $K_{I c}$ of concretes

\begin{tabular}{l|l|c|c}
\hline Concrete & Fracture toughness $K_{I c}\left[\mathrm{MN} / \mathrm{m}^{3 / 2}\right]$ & $s\left[\mathrm{MN} / \mathrm{m}^{3 / 2}\right]$ & $v[\%]$ \\
\hline FA-00 & $1.06-(100 \%$ - comparative concrete $)$ & 0.15 & 9.68 \\
FA-20 & $1.09-(102.8 \%$ in relation to FA-00 $)$ & 0.22 & 10.09 \\
FA-30 & $0.93-(87.7 \%$ in relation to FA-00 $)$ & 0.18 & 10.75 \\
\hline
\end{tabular}

Table 5. Fracture toughness $K_{\text {IIc }}$ of concretes

\begin{tabular}{llcc}
\hline Concrete & Fracture toughness $K_{I I c}\left[\mathrm{MN} / \mathrm{m}^{3 / 2}\right]$ & $s\left[\mathrm{MN} / \mathrm{m}^{3 / 2}\right]$ & $v[\%]$ \\
\hline FA-00 & $4.24-(100 \%$ - comparative concrete $)$ & 0.65 & 9.43 \\
FA-20 & $4.39-(103.5 \%$ in relation to FA-00 $)$ & 0.81 & 11.63 \\
FA-30 & $3.65-(86.1 \%$ in relation to FA-00 $)$ & 0.78 & 12.11 \\
\hline
\end{tabular}


parameters (Table 2) as well as reduced fracture toughness $K_{\text {IIIC }}$ (Table 3 ).

\section{Conclusions}

The following conclusions can be drawn from the present investigation:

1. The siliceous FA additives clearly change the antiplane shear fracture toughness $K_{\text {IIIC }}$.

2. $20 \%$ FA additive causes a small increase of $K_{\text {IIIc }}$ while $30 \%$ FA additive causes a significant decrease in fracture toughness.

3. The fracture surfaces of the specimens were planar.

4. Results of fracture toughness obtained at Mode I, Mode II and Mode III fracture are convergent qualitatively.

5. Proportions of stress intensity factors, which are $K_{I-}$ ${ }_{I I c} / K_{I c}=2.30-2.39$ and $K_{I I I C} / K_{I I c}=0.59$ indicate that the greater fracture toughness have concretes at the Mode II fracture, while the smallest one at Mode I fracture.

6. Designed and manufactured the special device for fracture toughness tests in the Mode III fracture proved to be very useful to carry out these studies.

\section{Acknowledgements}

This work was financially supported by Ministry of Science and Higher Education within the statutory research number $\mathrm{S} / 15 / 2017$.

\section{References}

Ahmaruzzaman, M. 2010. A review on the utilization of fly ash, Progress in Energy and Combustion Science 36(3): 327363. https://doi.org/10.1016/j.pecs.2009.11.003

Bazant, Z. P.; Prat, P. C. 1988. Measurement of mode III fracture energy of concrete, Nuclear Engineering and Design 106(1): 1-8. https://doi.org/10.1016/0029-5493(88)90265-8

Bazant, Z. P.; Prat, P. C.; Tabbara, M. R. 1990. Antiplane shear fracture tests (Mode III), ACI Materials Journal 87(1): $12-19$.

Bernardo, L. F. A.; Andrade, J. M. A.; Pereira-De-Oliveira, L. A. 2013. Reinforced and prestressed concrete hollow beams under torsion, Journal of Civil Engineering and Management 19(Supplement 1): S141-S152. https://doi.org/10.3846/13923730.2013.801895

Bharatkumar, B. H.; Raghu Prasad, B. K.; Ramachandramurthy, D. S.; Narayanan, R.; Gopalakrishnan, S. 2005. Effect of fly ash and slag on the fracture characteristics of high performance concrete, Materials and Structures 38(1): 63-72. https://doi.org/10.1007/BF02480576

Chindaprasirt, P.; Rukzon, S. 2008. Strength, porosity and corrosion resistance of ternary blend Portland cement, rice husk ash and fly ash mortar, Construction and Building Materials 22(8): 1601-1606. https://doi.org/10.1016/j.conbuildmat.2007.06.010

Giergiczny, Z.; Król, A. 2008. Immobilization of heavy metals $(\mathrm{Pb}, \mathrm{Cu}, \mathrm{Cr}, \mathrm{Zn}, \mathrm{Cd}, \mathrm{Mn})$ in the mineral additions containing concrete composites, Journal of Hazardous Materials 160(2-3): 247-255.

https://doi.org/10.1016/j.jhazmat.2008.03.007
Golewski, G. L. 2015. Studies of natural radioactivity of concrete with siliceous fly ash addition, Cement-Wapno-Beton [Cement-Lime-Concrete] 2: 106-114.

Golewski, G. L.; Sadowski, T. 2012. Experimental investigation and numerical modeling fracture processes under Mode II in concrete composites containing fly-ash additive at early age, Solid State Phenomena 188: 158-163. https://doi.org/10.4028/www.scientific.net/SSP.188.158

Golewski, G. L.; Sadowski, T. 2014. An analysis of shear fracture toughness $K_{I I c}$ and microstructure in concretes containing fly-ash, Construction and Building Materials 51: 207-214.

https://doi.org/10.1016/j.conbuildmat.2013.10.044

Golewski, G. L.; Golewski, P.; Sadowski, T. 2012. Numerical modeling crack propagation under Mode II fracture in plain concretes containing siliceous fly ash additive using XFEM method, Computational Materials Science 62: 75-78. https://doi.org/10.1016/j.commatsci.2012.05.009

Gorzelańczyk, T.; Hoła, J. 2015. Stress failure of cement concretes under compression - synthesis of knowledge, conclusions, Journal of Civil Engineering and Management 21(1): $1-10$. https://doi.org/10.3846/13923730.2014.929024

Grinys, A.; Vaičiukynienė, D.; Sivilevičius, H.; Pupeikis, D.; Ivanauskas, E. 2013. Fracture of concrete containing crumb rubber, Journal of Civil Engineering and Management 19(3): 447-455. https://doi.org/10.3846/13923730.2013.782335

Grinys, A.; Vaičiukynienè, D.; Augonis, A.; Sivilevičius, H.; Bistrickaite, R. 2015. Effect of milled electrical cable waste on mechanical properties of concrete, Journal of Civil Engineering and Management 21(3): 300-307. https://doi.org/10.3846/13923730.2015.1005019

Holschemacher, K. 2004. Hardened material properties of selfcompacting concrete, Journal of Civil Engineering and Management 10(4): 261-266. https://doi.org/10.1080/13923730.2004.9636318

Jacobsen, J. S.; Poulsen, P. N.; Olesen, J. F.; Krabbenhoft, K. 2013. Constitutive mixed mode model for cracks in concrete, Engineering Fracture Mechanics 99: 30-47. https://doi.org/10.1016/j.engfracmech.2013.01.004

Jing, Z.; Jin, F.; Hashida, T.; Yamasaki, N.; Ishida, E. H. 2008. Influence of addition of coal fly ash and quartz on hydrothermal solidification of blast furnace slag, Cement and Concrete Research 38(7): 976-982. https://doi.org/10.1016/j.cemconres.2008.01.017

Jóźwiak-Niedźwiedzka, D.; Brandt, A. M.; Ranachowski, Z. 2012. Self-healing of cracks in fibre reinforced mortar beams made with high calcium fly ash, Cement-WapnoBeton [Cement-Lime-Concrete] 1: 38-49.

Kamiński, M.; Pawlak, W. 2011. Load capacity and stiffness of angular cross section reinforced concrete beams under torsion, Archives of Civil and Mechanical Engineering 11(4): 885-903. https://doi.org/10.1016/S1644-9665(12)60085-5

Konkol, J.; Prokopski, G. 2014. The influence of the age of concretes with FBC fly ash or metakaolinite additives on their strength properties, Roads and Bridges 13(1): 49-67.

Kosior-Kazberuk, M.; Lelusz, M. 2007. Strength development of concrete with fly ash addition, Journal of Civil Engineering and Management 13(2): 115-122.

Kurdowski, W. 2014. Cement and concrete chemistry. Netherlands, New York, USA: Springer. 699 p. https://doi.org/10.1007/978-94-007-7945-7

Lam, L.; Wong, Y. L; Poon, C. S. 1998. Effect of fly ash and silica fume on compressive and fracture behaviors of concrete, Cement and Concrete Research 28(2): 271-283. https://doi.org/10.1016/S0008-8846(97)00269-X 
Lee, H. J.; Lee, J. H.; Kim, D. G. 2012. Study on the change in microstructure of fly ash concrete depending on ages and degree of hydration using XRD and SEM, Advanced Materials Research 486: 350-355.

https://doi.org/10.4028/www.scientific.net/AMR.486.350

Liu, M.; Wang, Y. 2011. Prediction of the strength development of fly ash concrete, Advanced Materials Research 150-151: 1026-1033.

Lopes, A. V.; Lopes, S. M. R.; do Carmo, R. N. F. 2014. Stiffness of reinforced concrete slabs subjected to torsion, Materials and Structures 47(1-2): 227-238. https://doi.org/10.1617/s11527-013-0057-x

Mehta, P. K.; Monteiro, P. J. M. 1987. Effect of aggregate, cement, and mineral admixture on the microstructure of the transition zone, MRS Proceedings 114: 65-75.

Meyer, C. 2009. The greening of the concrete industry, Cement and Concrete Composites 31(8): 601-605. https://doi.org/10.1016/j.cemconcomp.2008.12.010

Miannay, D. P. 1998. Fracture mechanics. New York, USA: Springer-Verlag. 345 p. https://doi.org/10.1007/978-1-4612-1740-4

Nadeem, A.; Memon, S. A.; Lo, T. Y. 2014. The performance of fly ash and metakaolin concrete at elevated temperatures, Construction and Building Materials 62: 67-76. https://doi.org/10.1016/j.conbuildmat.2014.02.073

Nasibulin, A. G.; Koltsova, T.; Nasibulina, L. I.; Anoshkin, I. V.; Semencha, A.; Tolochko, O. V.; Kauppinen, E. I. 2013. A novel approach to composite preparation by direct synthesis of carbon nanomaterial on matrix or filler particles, Acta Materialia 61(6): 1862-1871.

https://doi.org/10.1016/j.actamat.2012.12.007

Poon, C. S.; Lam, L.; Wong, Y. L. 2000. A study on high strength concrete prepared with large volumes of low calcium fly ash, Cement and Concrete Research 30(3): 447-455. https://doi.org/10.1016/S0008-8846(99)00271-9

Rathish Kumar, P.; Sumanth Reddy, C.; Saleem Baig, Md. 2014. Compressive strength performance of high strength concretes using binary supplementary cementitious materials, Cement-Wapno-Beton [Cement-Lime-Concrete] 1: 8-16.

Rudžionis, Ž.; Ivanauskas, E. 2004. Investigations into effective fly ash used in concrete, Journal of Civil Engineering and Management 10(4): 303-309. https://doi.org/10.1080/13923730.2004.9636323

Sabet, F. A.; Libre, N. A.; Shekarchi, M. 2013. Mechanical and durability properties of self consolidating high performance concrete incorporating natural zeolite, silica fume and fly ash, Construction and Building Materials 44: 157184. https://doi.org/10.1016/j.conbuildmat.2013.02.069

Sadowski, T.; Golewski, G. L. 2008. Effect of aggregate kind and graining on modeling of plain concrete under compression, Computational Materials Science 43(1): 119126. https://doi.org/10.1016/j.commatsci.2007.07.037
Sekulic, Z.; Popov, S.; Duricic, M.; Rosic, A. 1999. Mechanical activation of cement with addition of fly ash, Materials Letters 39(2): 115-121. https://doi.org/10.1016/S0167-577X(98)00226-2

Snelson, D.; Wild, S.; O'Farrell, M. 2011. Setting times of Portland cement-metakaolin-fly ash blends, Journal of Civil Engineering and Management 17(1): 55-62. https://doi.org/10.3846/13923730.2011.554171

Song, L.; Huang, S. M.; Yang, S. C. 2004. Experimental investigation on criterion of three-dimensional mixed-mode fracture for concrete, Cement and Concrete Research 34(6): 913-916.

https://doi.org/10.1016/j.cemconres.2003.10.013

Stehlík, M. 2013. Testing the strength of concrete made from raw and dispersion-treated concrete recyclate by addition of additives and admixtures, Journal of Civil Engineering and Management 19(1): 107-112. https://doi.org/10.3846/13923730.2012.734853

Vejmelkova, E.; Pavlikova, M.; Keepert, M.; Kersner, Z.; Rovnanikova, P.; Ondracek, M.; Sedlmajer, M.; Cerny, R. 2009. Fly ash influence on the properties of high performance concrete, Cement-Wapno-Beton [Cement-LimeConcrete] 4: 189-204.

Wang, J. J.-A.; Liu, K. C.; Naus, D. A. 2010. A new test method for determining the fracture toughness of concrete materials, Cement and Concrete Research 40(3): 497-499. https://doi.org/10.1016/j.cemconres.2009.09.019

Xia, C.; Jianjun, Y.; Huaquan, Y. 2012. Influence of aggregates on cracking sensitivity of concrete, Applied Mechanics and Materials 204-208: 3299-3302.

Xu, H.; Chen, Z.; Xu, B.; Ma, D. 2012. Impact of low calcium fly ash on steel corrosion rate and concrete steel-interface, The Open Civil Engineering Journal 6: 1-7. https://doi.org/10.2174/1874149501206010001

Yu, R.; Spiesz, P; Brouwers, H. J. H. 2015. Development of an eco-friendly ultra-high performance concrete (UHPC) with efficient cement and mineral admixtures uses, Cement and Concrete Composites 55: 383-394. https://doi.org/10.1016/j.cemconcomp.2014.09.024

Zhang, M. H. 1995. Microstructure, crack propagation, and mechanical properties of cement pastes containing high volumes of fly ashes, Cement and Concrete Research 25(6): 1165-1178. https://doi.org/10.1016/0008-8846(95)00109-P

Zhang, P.; Li, Q.-F. 2013. Effect of silica fume on fracture properties of high-performance concrete containing fly ash, Proceedings of the Institution of Mechanical Engineers, Part L: Journal of Materials: Design and Applications 227(4): 336-342. https://doi.org/10.1177/1464420712456514

Grzegorz Ludwik GOLEWSKI. PhD, DSc, Eng., Associate Professor in the Civil Engineering and Architecture Faculty at Lublin University of Technology (Poland). Obtained his diploma in Civil Engineering at LUT in 1999. Currently working at LUT, Department of Structural Engineering. Member of Polish Society of Composite Material (PTMK) and Polish Association of Building Engineers and Technicians (PZITB). Chairmen of the wheel 45 PZITB at LUT. His research interest include: fracture toughness of concrete, concretes with mineral additives, nanotechnology in concrete. 